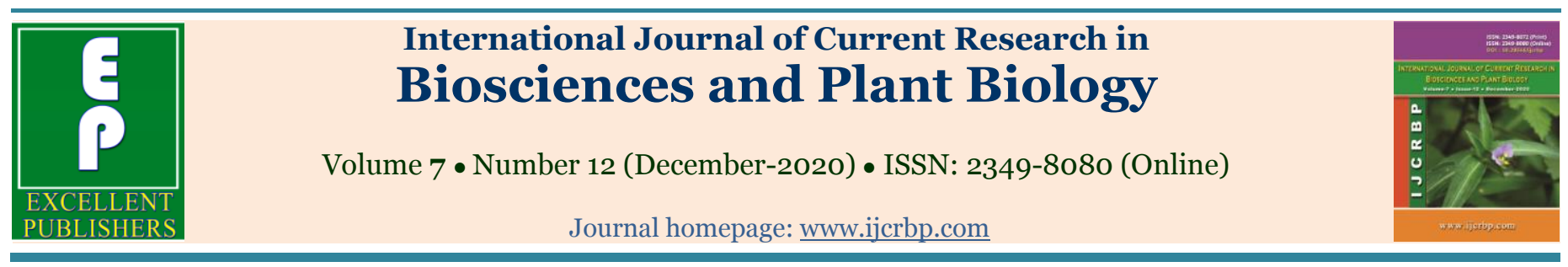

\title{
Fish production enhancement through modern fishery technology around Adami Tullu Jiddo Kombolcha District of Lake Ziway
}

\author{
Lemma Abera Hirpo*
}

Oromia Agricultural Research Institute, Batu Fish and Other Aquatic Life Research Center, Batu, Ethiopia

*Corresponding author e-mail: negrofarm@gmail.com

\begin{tabular}{|c|c|}
\hline Article Info & ABSTRACT \\
\hline $\begin{array}{l}\text { Date of Acceptance: } \\
11 \text { November } 2020\end{array}$ & \multirow{3}{*}{$\begin{array}{l}\text { Lake Ziway is one of the lakes in the rift valley which are used for multiple purposes } \\
\text { including fishing. The lake has several commercially important fish species for fisheries. } \\
\text { However, the fishery of the lake seems to be threatened by anthropogenic and climatic } \\
\text { factors, which in turn affect biotic factors as reflected in fish catch. The study was } \\
\text { conducted to enhance fish production through available modern fishery technologies. } \\
\text { The technologies were gillnet of } 10 \mathrm{~cm} \text { mesh size for Oreochromis niloticus and } 12 \mathrm{~cm} \\
\text { mesh size for Cyprinus carpio; boats made of recycling plastic bottles; retaining cage } \\
\text { and smoking technology. One farmer research extension groups (FREG) that had } 72 \\
\text { fishermen members, with consideration to gender participation was formed and } \\
\text { training on each technology was given for appropriate utilization of the fishery } \\
\text { resources of the lake. Hence, the result revealed that tabled sized fishes were caught } \\
\text { through appropriate fishing gear to avoid over exploitation of the resources and quality } \\
\text { product were obtained by applying those post-harvest technologies. Therefore, the } \\
\text { study confirmed that the modern fishery technology is highly important for better } \\
\text { utilization of the fishery resources and needs to be promoted as one of the capture } \\
\text { fisheries strategies that can enhance fish production. }\end{array}$} \\
\hline Keywords & \\
\hline $\begin{array}{l}\text { Fishes } \\
\text { Fishing gears } \\
\text { Lake Ziway } \\
\text { Post-harvest technologies }\end{array}$ & \\
\hline
\end{tabular}

\section{Introduction}

Ethiopia has a number of lakes and rivers with substantial quantity of fish stocks. There are 10 major lakes with a total area of $7,400 \mathrm{~km}^{2}$ and major rivers a combined length of 7,185 $\mathrm{km}$ (Brook Lemma, 2012). Many artificial water bodies have also been stocked with fish for fishery. Most of the lakes are located in the Ethiopian Rift Valley, which is part of the Great East African Rift Valley system.

The natural resource of the Rift Valley has immense economic and cultural values. These lakes are considered as centers of biodiversity, corridors of countless migratory birds; and are used in ameliorating the effects of drought and protein shortage for the population in the region (Zinabu, 1998; 2002; 2003). Lake Ziway is one of the lakes in the rift valley used for multiple purposes like irrigation, fishing, domestic water supply, transportation, recreation and supply of fresh water to Lake Abijata through the out flowing of Bulbula River. Although its importance is in the wide range of purposes, the fishery resources are not utilized appropriately for the proper management of the lake. 
There are seven indigenous fish species in the lake comprising Barbus paludinosus, Garra dembecha, Garra makiensis, Labeobarbus ethiopicus, Labeobarbus intermedius, Labeobarbus microterolepis and Oreochromis niloticus (Golubtsov et al., 2002; Abebe, 2010; Jacobus et al., 2012). The lake also harbors five exotic fish species (Tilapia zillii, Cyprinus carpio, Carassius carassius and Carassius auratus) which were introduced to enhance its production, and Clarias gariepinus that slipped into the lake accidentally (Golubtsov et al., 2002). Therefore, the lake has several important fish species for fisheries.

Lake Ziway had a high fish yield potential of 3000 to 6680 tons per year (FAO, 1982). The fisheries activity in the lake was intensified through funding acquired from Lake Fisheries Development Project (LFDP) with the European Union (EU). The fisheries production has been the second largest from the Rift Valley lakes, which accounted for 3180 tons, next to Lake Chamo that produced 4500 tons per year (LFDP, 1998). However, the annual fish catch of the lake shows different trends at different times and currently became less than 1,000 tons per year (Lemma et al., 2018). According to Lemma (2016), there was a continuous decline in the annual catch of some fish species like $O$. niloticus from the lake since 1997. On the other hand an increase of C. gariepinus was observed in the fishermen catches since 2010 (Mathewos, 2011). In the same way, very recently increase in the catches of $C$. carpio was recorded (Lemma et al., 2014).

The fishermen used wooden boats for fishing and motorized boats for collecting catch from reed-boat fishermen in some areas. The use of illegal fishing gears, such as beach seine with smaller mesh size, has been widely spread and poorly monitored. Recent studies have shown that $96 \%$ of the gears operating in the lake are under the recommended mesh size and traditional means of fishery technology (Mathewos, 2013). Thus, there is a need to apply an appropriate fishery technology to meet the increasing demand for food from fish resources, and maximize the utilization of the available untapped fishery resources. The objective of the study was therefore, to enhance fish production through available modern fishery technologies in the lake.

\section{Materials and methods}

\section{Description of study area}

Lake Ziway belongs to the Central Ethiopian Rift. It is the third largest lake in the Ethiopian part of the Rift Valley and fourth in the country in terms of surface area. Lake Ziway is bordered by two administrative zones of Oromia Regional State. The Western part belongs to East Shoa Zone while the Eastern part belongs to Arsi Zone. The Western shore is shared by two districts, namely, Adami Tullu Jiddo Kombolcha and Dugda. The Eastern shore belongs to only Ziway Dugda district. On the average, the lake is located at about $163 \mathrm{~km}$ south of Addis Ababa, at an elevation of 1650 meter above sea level at $7^{\circ} 89^{\prime}-8^{\circ} 05^{\prime} \mathrm{N}$ latitude and $38^{\circ} 72^{\prime}-38^{\circ} 92^{\prime} \mathrm{E}$ longitude. The lake is shallow and has an open water area of $434 \mathrm{~km}^{2}$ and shoreline length of $137 \mathrm{~km}$ (Von Damm and Edmond, 1984). The maximum length and width of the lake is 32 $\mathrm{km}$ and $20 \mathrm{~km}$, respectively (LFDP, 1997). Location of Ethiopia in the Horn of Africa, the Ethiopian Rift Valley Lakes including Ziway Lake is shown in Fig. 1.

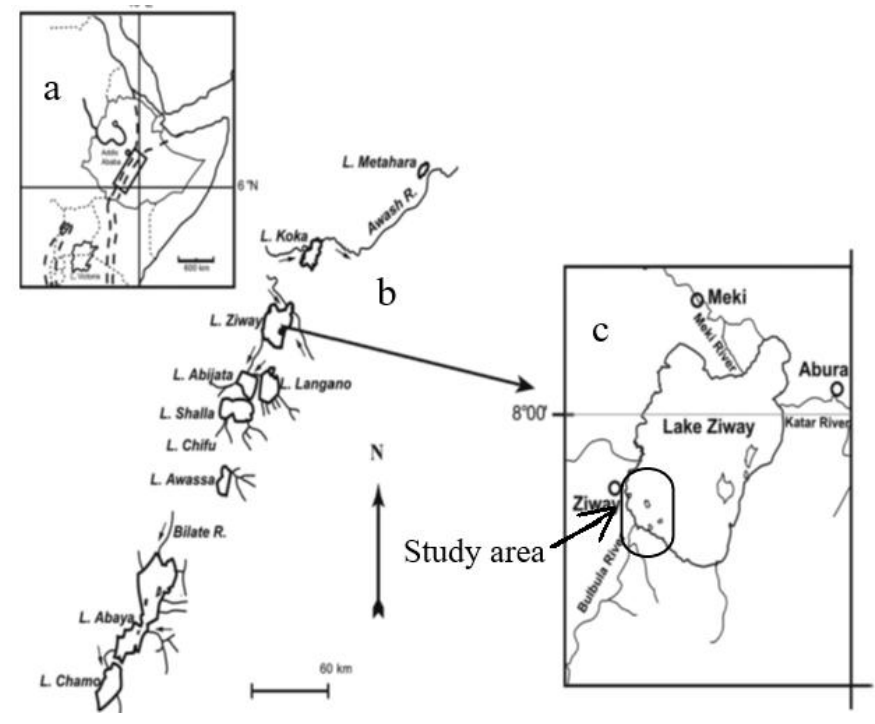

Fig. 1: (a) Location of Ethiopia in the Horn of Africa, (b) Location of Ethiopian Rift Valley Lakes and (c) Lake Ziway (Source: Lemma, 2016)

Currently the lake has four commercially important fish species for fisheries (O. niloticus, $C$. carpio, C. carassius and C. gariepinus) (Fig.2). 

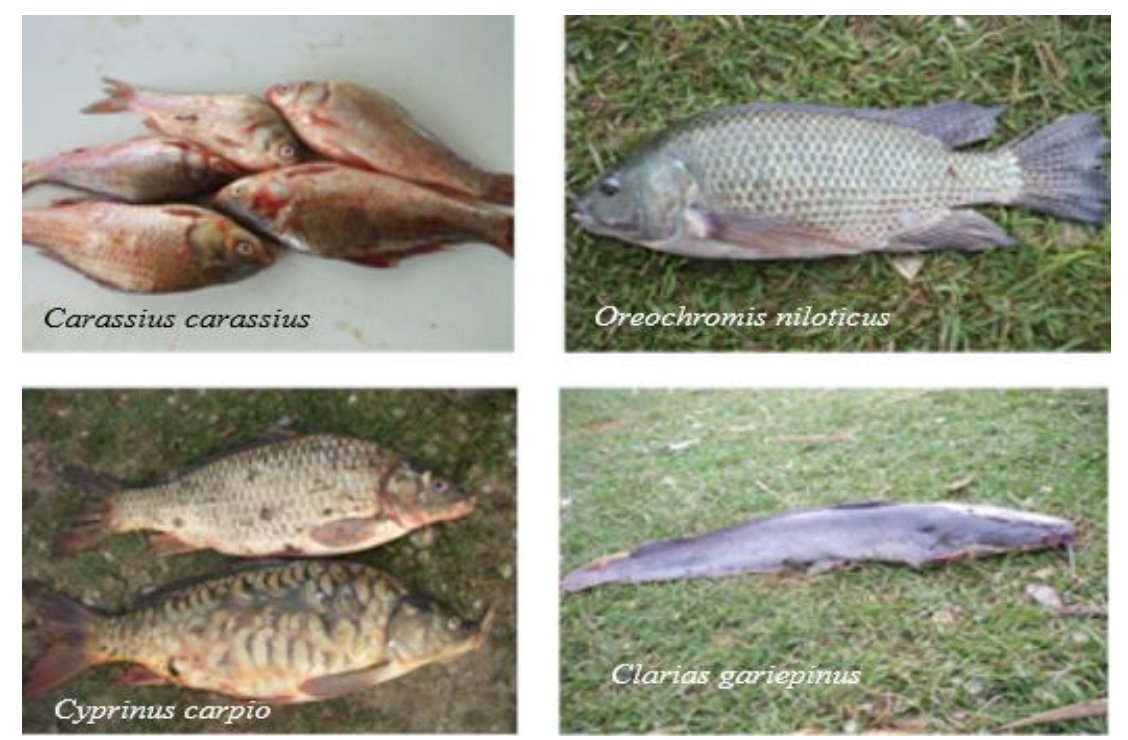

Fig. 2: Commercially important fish species in Lake Ziway.

\section{Selection of fishery cooperative and training}

Ziway-Batu Fishermen Cooperative that actively operate in fishing activity at landing site was purposively selected. The members of the cooperative were seventy-two. Training was given for the selected cooperative members on the technologies (gill net, boat made up of waste plastic bottles, retaining cage and Smoking technology) starting from the beginning of the activity through the ongoing process. Interviews were conducted through questionnaire to assess the existing constraints of the fisheries in the lake.

\section{Established fishery management committee}

The fisheries management committee was established from the fishermen and other stakeholders who are directly related to the sector. The approach was like co-management approach, where responsibility was shared between the government and other stakeholders, to harness the knowledge and capacities of those who have a shared interest in the sustainability of a fishery towards promoting the common end. The approach, therefore, can be considered as a response to manage fisheries, enforce regulations and responds to the desire of fishing communities to empower them.

\section{Fishing gear technologies}

There were fishery technologies availed for better utilization of the fishery resources. Hence, gill nets of different mesh size (10 $\mathrm{cm}$ for $O$. niloticus and 12 $\mathrm{cm}$ for $C$. carpio) were used for fishing with boat made up of waste plastic bottles (Fig. 3).
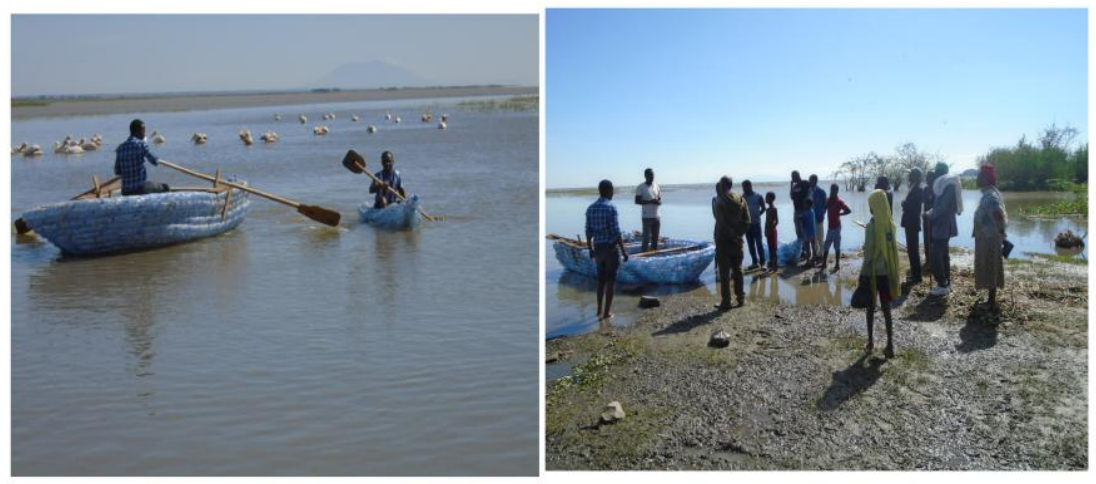

Fig. 3: Boat made up of waste plastic bottle for fishing. 


\section{Fishing gears selectivity and length at maturity}

The gears were set for fishing in the afternoon (5:00 pm) and collected in the next morning (6:00 am). Knowledge of the reproductive biology of exploited fish species was an essential prerequisite for effective fisheries management. Size at first maturity (commonly abbreviated as $\mathrm{L}_{50}$ ) is one of the fundamental variables of fish life history that determines the reproductive potential of a stock and its capacity to withstand exploitation (Stearns, 1976). It refers to the length at which $50 \%$ of the population is mature. $\mathrm{L}_{50}$ is most widely used parameter for the definition of harvest strategies to optimize exploitation and/or ensure sustainability (Froese, 2004). Its analysis was made after classifying data by length class. Then the percentages of the fishes with mature gonads were plotted against length to estimate $\mathrm{L}_{50}$ (Tweddle and Turner, 1977).

\section{Retaining cage}

Circular retaining cage was constructed from net of mesh size about $1 \mathrm{~cm}^{2}$ as indicated in Fig. 4 . The cage had a volume of $2 \mathrm{~m}^{3}$ with metal ring from the inner wall. Harvested fishes were immediately transferred to the retaining cage while it was in the water. The retaining cage with the fish was set at mean depth of 1.5 meters using anchors. The fish were taken out and fish that were alive, died and spoiled were identified and recorded separately.

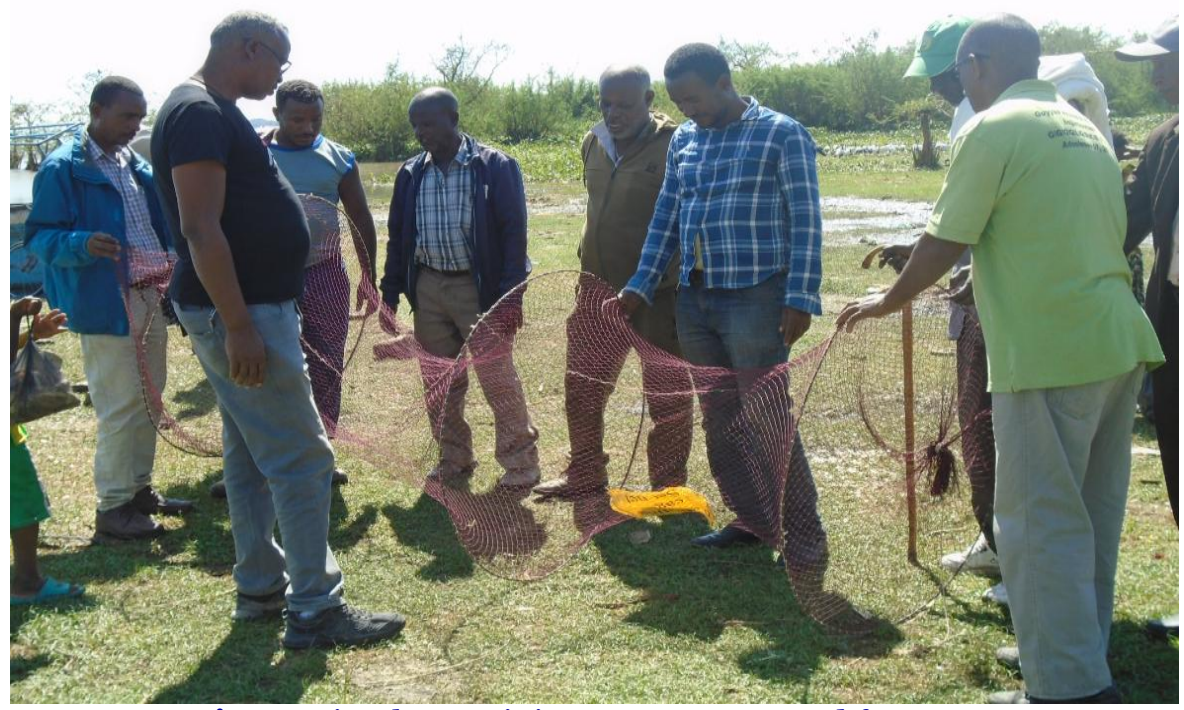

Fig. 4: Circular retaining cage constructed from net.

\section{Chorkor smoker}

The chorkor smoker (oven) was constructed from locally available materials at low cost. It consists of a combustion chamber and a smoking unit with a set of trays. The combustion chamber was rectangular, twice as long as it is wide and divided by a wall down the middle and with two stokes holes in the front (Fig 5). The combustion chamber is the base of the smoker and was generally constructed from mud. The top of the oven wall is square, level and flat. The smoker was designed in such a way that the woods frame of the trays rest along the middle line of the base walls. The capacity of Chorkor smoker was $10 \mathrm{~kg}$ of prepared fish per trays. The distance of the fire from the base to the last tray was $50 \mathrm{~cm}$.

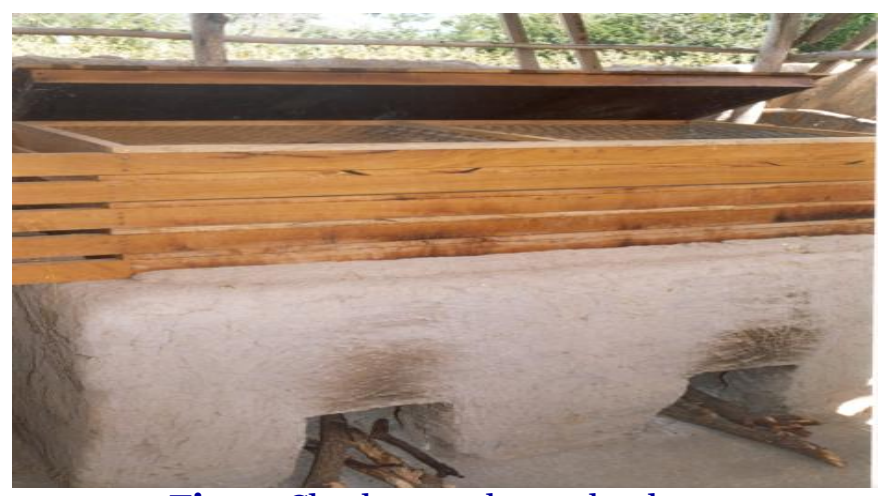

Fig. 5: Chorkor smoker technology. 


\section{Processing shade and tables}

It is common that fishermen process the fish on the ground without any shade. The processing shade with a total area of $210 \mathrm{~m}^{2}$ to accommodate processing tables was constructed around the selected landing site (Fig. 6).

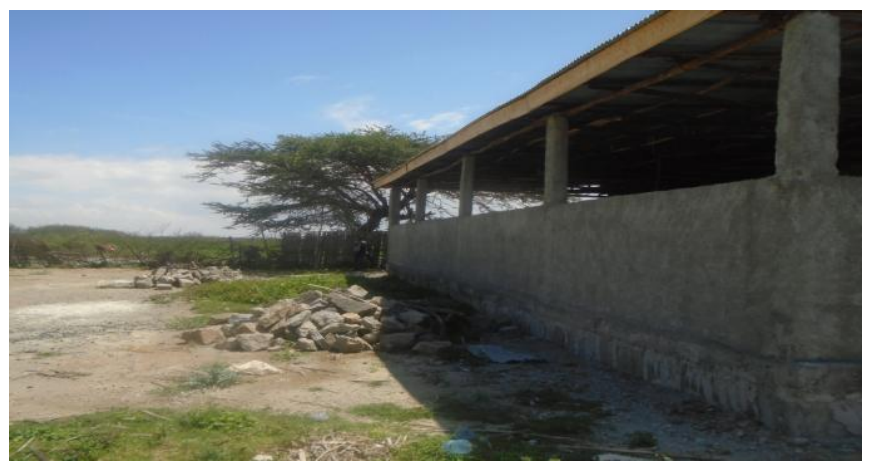

Fig. 6: Constructed processing shade around the lake.

\section{Results and discussion}

\section{Major constraints of the fishery in the lake}

Open access to the resource and pollution were the most common problems on the landing site (Fig. 7). Pollution of the lake was taking place due to improper farming methods and poor tillage systems, which contribute towards the erosion of top soils of the steep cultivated land around the catchment of eastern part of the lake. Urbanization and human settlement are amongst the most serious problems around the lake. Associated industrial development was also problematic in the lake, intensifying pollution, especially around the study site. Farming along the lakeshore not only disturbs the ecology of the shore but also exacerbates siltation and increases turbidity Lemma (2016).

Lack of fishery technologies is also a common constraint of fishery in the lake. Twenty five percent of the fishermen indicated that they face technological constraints (Fig.7). Fishes from the lake were usually caught and transported by reed boats. In most cases these boats were old and inefficient (personal observation). Motors for boats were not easily available being one of the major technological problems. Floats and lead rope used with nets were also difficult to obtain for appropriate fishing practices.

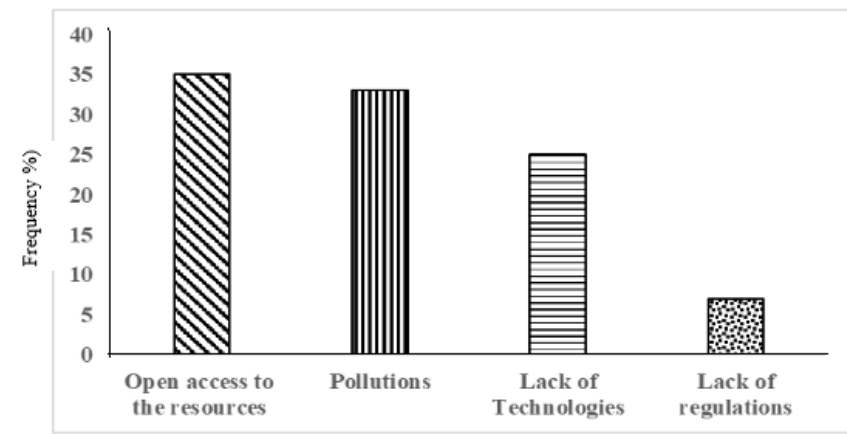

Fig. 7: Major constraints of Lake Ziway fishery according to responses of fishermen.

According to the survey and personal observations, fishing on Lake Ziway was predominantly artisanal and the fishermen use non-motorized traditional boats and gears. In addition, key informants revealed that some fishermen were using destructive fishing gears of small mesh sized beach seines. Personal observations also corroborated this. The small mesh size indiscriminately catches both the immature and mature fishes. This indiscriminate immature fish catch endangers the reproductive capacity of the stock that directly affects the resources of the lake.

There was a critical shortage of processing facilities. This intensifies the spoilage process. There are limited buyers at the area with limited capacity. This had impact on the price of fish in such a way that fishermen were forced to sell the products with cheaper price before they lose of the quality. There are limited options for preservation and improving the shelf life of fish products.

In the area, the market issues depend on physical access to landing points, number of retailers in the area and the amount of catch (personal observation). Low prices were paid for fishes, particularly due to the loss of quality because of limited options for processing and conservation facilities in the study area.

\section{Fishing gear technologies}

\section{Length at first maturity and fishing gears selectivity}

Length of first maturity $\left(\mathrm{L}_{50}\right)$ was estimated to be $28 \mathrm{~cm}$ FL for female and $27 \mathrm{~cm}$ FL for male for $C$. carpio, whereas it was $17.9 \mathrm{~cm}$ and $17.3 \mathrm{~cm}$ 
respectively, for female and male fish of $O$. niloticus fish species (Fig. 8). On the average, males appeared to attain sexual maturity at a relatively smaller size than females in both species. As reported for both temperate and tropical aquatic ecosystems, males attain maturity at a smaller size than femailes (Tempero et al., 2006; Britton et al., 2007). Size at first sexual maturity of $O$. niloticus in Lake Ziway was lower than those in Lake Koka and Langano. This might be due to the high fishing pressure on the former lake.

The catch size frequency distributions of the two fish species caught by the two gillnet mesh sizes were indicated in figure 7 . Totally, 530 gill nets of different mesh size were operated for fishing of different fish species. From the measurements total gill nets measurements that were taken from 54 randomly selected boats, all were found to be of less than $10 \mathrm{~cm}$ mesh size. The range of mesh sizes used by the fishermen varies between $6-10 \mathrm{~cm}$ stretched mesh sizes. The current mesh size used in the lake was lower than the minimum mesh size used to capture $C$. carpio and $O$. niloticus at their $\mathrm{L}_{50}$ around $27 \mathrm{~cm}$ and $17 \mathrm{~cm}$ respectively for both sexes (Figure 9 and 10). Hence, care should be taken not to lower the mesh size any further as the immature fishes will be affected by the fishery.
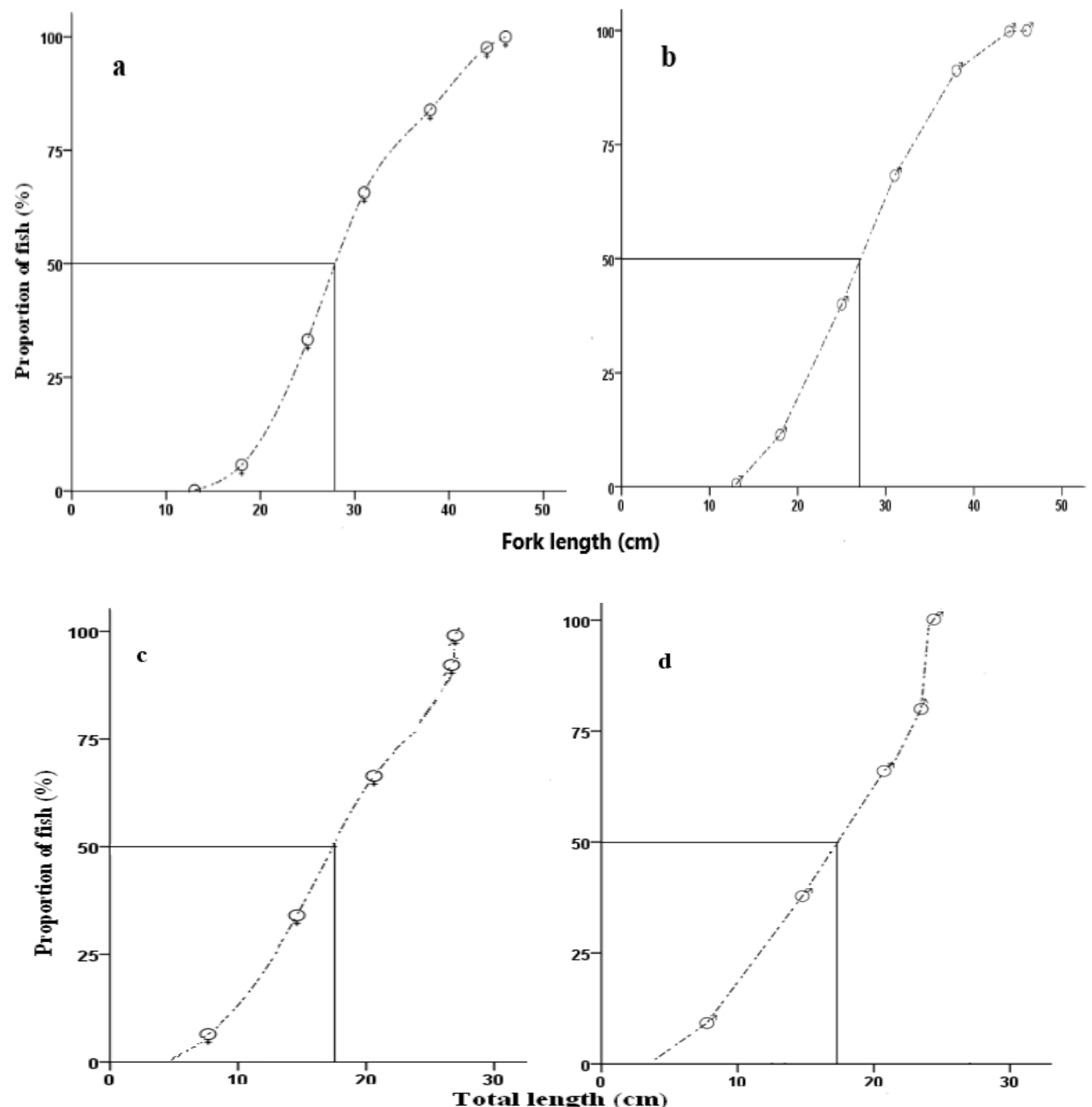

Fig. 8: The proportion of fish in different length groups of females (a) and males (b) of C. carpio; females (c) and males (d) of O. niloticus in Lake Ziway. 


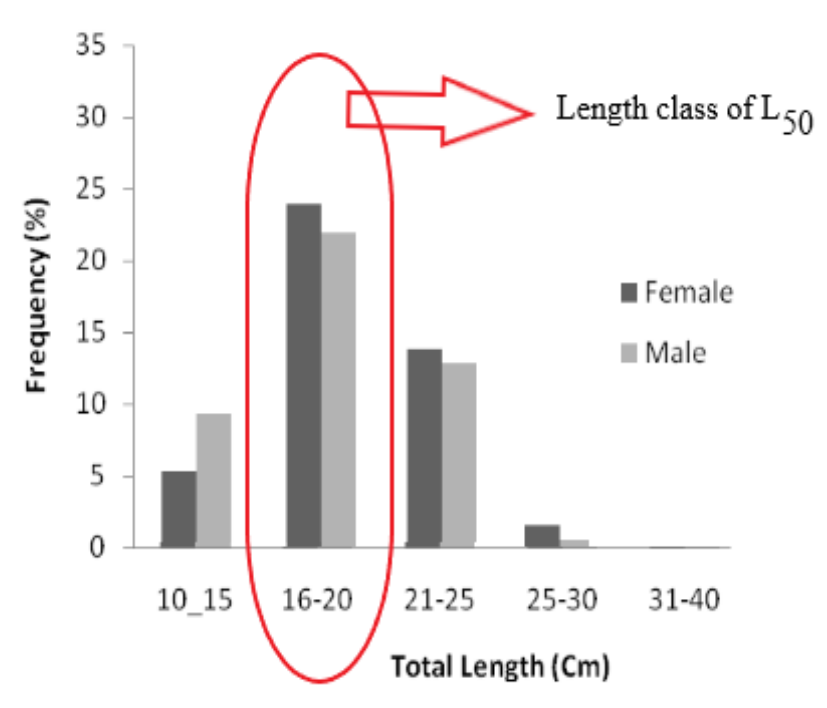

Fig. 9: Number of fish catch per length class of O.niloticus using $10 \mathrm{~cm}$ mesh size gill net.

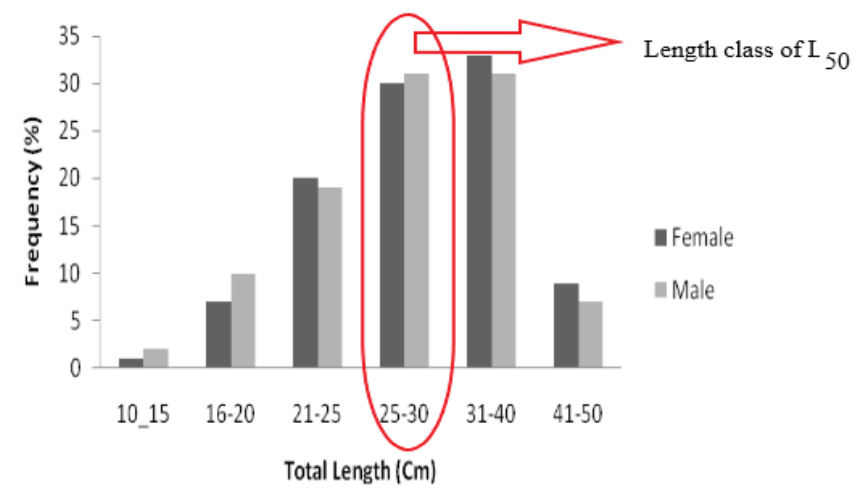

Fig. 10: Number of fish catch per length class of C. carpio using $12 \mathrm{~cm}$ mesh size gill net.

The results of gill selectivity show that the use of gillnets with mesh sizes that select fish below the size at first maturity $\left(\mathrm{L}_{50}\right)$ of the target resources for both species that reduced the spawning stock (Fig. 9 and Fig. 10).

\section{Retaining cage}

On average $250 \mathrm{~kg}$ of lived O.niloticus were harvested from the lake and transferred in to the retaining cage. After 12 hours on average $241 \mathrm{~kg}$ of fish were sold as fresh marketable fish. Death recorded was $5 \%$ of the total fish but fish were still fresh and marketable, whereas spoiled fish (fish discarded) during the experimental period was $1 \%$ (Fig. 11). The discarded amount was almost similar with to what found by Getachew, 2013 (1.3\%) in lake Beseka and much smaller than what was found (30\%) by Yared et al. (2006). Generally, the overall performance of the cage was rated by the fishermen as best material in reducing postharvest loss at landing site.

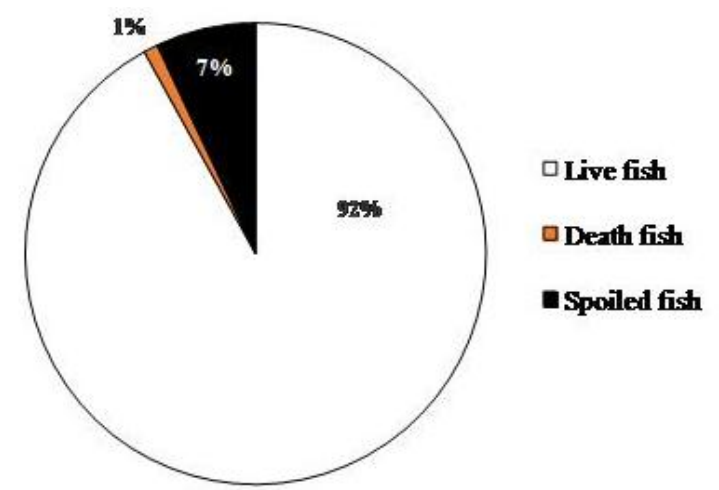

Fig. 11: Percent spoiled, dead, and live fish on the landing site.

\section{Smoking technology}

In principle, 37 and $40 \mathrm{~kg}$ firewood was used to smoke $100 \mathrm{~kg}$ of prepared fish using the smoker to reduce the moisture content to 14 and $40 \%$ in 3 and 4 hours, respectively. During the study period all fish smoked with the oven were good in quality and marketable products. The final product obtained by "wet hot" smoked fish can be stored for 3 months under $-5^{\circ} \mathrm{C}$ and from 6 to 9 months for "dry hot" smoked fish without being affected by bacteria and molds.

The Chorker smoker has proved to be useful innovation in fresh water fisheries, because of being easily adjustable to local needs and conditions. The technology was built from bricks made of mud with teff straw. These bricks were more durable and have better heat retention properties, which further improves fuel efficiency. The smoker was easy to operate and time saving, thus alleviating the need for more human power. It has reduced labor requirements by about 30\% and fire wood use by about the same. Smoking gives also an appealing smoked color and smoky flavor to the fish.

\section{Training of farmers and other stakeholders}

Multidisciplinary research team (Culture fishery, fishery extension and socio-economic) and other stakeholders from zonal and district Agricultural 
offices have actively participated in delivering the training by sharing their experience and knowledge. Development agents, experts and farmers were participated on the training given on production, management and post-harvest handling technologies of the fishery.

Table 1. Type of profession and number of training participants.

\begin{tabular}{llll}
\hline \multirow{2}{*}{ Professionals } & \multicolumn{2}{l}{ Participants } & \multirow{2}{*}{ Total } \\
\cline { 2 - 4 } & Male & Female & \\
\hline Farmers & 64 & 8 & 72 \\
Das & 1 & - & 1 \\
Experts & 4 & - & 4 \\
Total & 69 & 8 & 77 \\
\hline
\end{tabular}

Among the training participant stakeholders, $83 \%$ were farmers of which $11 \%$ were females (Table 1 ). Unlike the other economic activities where both male and female can engage, fishing activity was solely carried out by male due to the labor intensive nature of the work. Different extension materials were prepared and distributed for the participants. During the training, different questions, opinions and suggestion were raised and reacted up on by concerned bodies. Most farmers showed high interest towards the technologies of capture fishery, because of better income generation as compare to other agricultural commodities. Generally, all farmers were very much interested to get the technologies for their future fishery production. Therefore, all concerned bodies were shared their responsibilities for the future interventions based on the assessed major fishery constraints to be addressed with respected to the lake.

\section{Conclusions and recommendations}

The fish yielding status of Lake Ziway has changed over time. Currently, the contribution of $O$. niloticus has decreased. This is due to the increase in effort applied through time and due to other anthropogenic impacts exerted on the lake. Fishing technology on Lake Ziway was not modern in its nature and only makes use of traditional boats of rafts and wooden manual boat. The fishery of this lake was not under any government regulations. The lake holds the same management system as the other lakes, open access.

In Lake Ziway, a large number of small sized fish of all species are being exploited and hence proper management actions are required to protect the immature fish. Particularly, capture size of the stock should be determined taking into consideration the size at first maturity of the target fishes. Thus, management tools like closed seasons, catch quota restriction, mesh size regulations, gear restrictions and limits on the number of fishers has to be continuously implemented to ensure sustainable exploitation of the stocks.

The fishermen use planked canoes for fishing activity. The fishes were exposed to direct sun and wind. The hygiene of the boats was also poor. On landing sites, the fishes were dumped on the ground where they are sold to buyers. In general, before introduction of the improved technology, there were no proper fish handling and preserving facilities both on boat and landing sites and the product were easily spoiled and discarded on the ground being a source of different pollutions. As a result of the introduction of these technologies some improvements on the production of fishes as well as on post-harvest products have been observed. Therefore, the fishermen must apply these recommended technologies (those appropriate fishing gears and post-harvest technologies for the better utilization of the resources.

\section{Conflict of interest statement}

Author declares that there is no conflict of interest.

\section{References}

Abebe, G., 2010. Labeobarbus ethiopicus. The IUCN Red List of Threatened Species. Version 2015.1. < www.iucnredlist.org >. Down loaded on 12 June 2015.

Britton, J., Boar, R., Grey, J., Foster, J., Lugonzo, J., Harper, D., 2007. From introduction to fishery dominance: the initial impacts of the invasive carp Cyprinus carpio in Lake Naivasha, Kenya. J. Fish Biol. 71, 239-257.

Brook Lemma, 2012. Report on the Value Chain Assessment of the Fishery Sector in Ethiopia. Food and Agriculture Organization SubRegional Office for Eastern Africa Addis Ababa. 131p.

Golubtsov, A., Dgebuadze, Y., Mina, M., 2002. Fishes of the Ethiopian rift valley. In: 
Ethiopian rift valley Lakes. pp. 167-256 (Tudorance, C. and Taylor, W.D. eds). Backhuys publishers, Leiden.

FAO (Food and Agriculture Organization of the United Nations), 1982. The production of fish meal and fish oil. Fishery industries division. FAO fishery technical paper 142.

Lemma, A., Abebe, G., Brook Lemma, 2014. Composition of commercially important fish species and some perspectives into the biology of the African Catfish Clarias gariepinus (Burchell), Lake Ziway, Ethiopia. Int. J. Adv. Res. 2, 864-871.

Lemma, A., 2016. Reproductive biology of Oreochromis niloticus in Lake Beseka, Ethiopia. J. Cell Anim. Biol. 9, 116-120.

Lemma, A., 2018. The impact of climate change on fisheries in the tropics. Int. J. Fish. Aquatic Stud. 6(1), 122-127.

LFDP, 1997. Lake Management Plans. Lake Fisheries Development Project, Phase II: Working Paper 23. Ministry of Agriculture, Addis Ababa.

LFDP, 1998. Fisheries Report, Phase II. Animal and Fisheries Resources Development Department (MOA). Addis Ababa, Ethiopia, 61p.

Mathewos, H., 2013. Reproductive aspects of common carp (Cyprinus carpio L, 1758) in a tropical reservoir (Amerti: Ethiopia). J. Environ. Microbiol. 1, 114-118.
Tweddle, D., Turner, J., 1977. Age, growth and natural mortality rates of some cichlid fishes of Lake Malawi. J. Fish Biol. 10, 385-398.

Tempero, G., Ling, N., Hicks, B., Osborne, M., 2006. Age composition, growth, and reproduction of koi carp (Cyprinus carpio) in the lower Waikato region. J. Mar. Freshwater Res. 40, 571-583.

Yared, T., Abera, D., Ahmed, M., 2006. Kinds and levels of post harvest losses and the possible ways to reduce the loses in Lake Ziway. Ethiopian Society of Animal Production. Addis Ababa. pp. 141-148.

Zinabu, G., 1998. Human Interactions and Water Quality in the Horn of Africa. In: Science in Africa-Emerging Water Management Problems. A publication of the symposium at the 1998 American Association for the Advancement of Science Annual Meeting, Philadelphia, Pennsylvania, pp.47-61.

Zinabu, G., 2002. The Ethiopian Rift Valley Lakes: Major Threats and Strategies for Conservation. In: Ethiopian rift valley lakes. Backhuys publishers, Leiden, pp. 259-271.

Zinabu, G., 2003. Human Interactions and Water Quality in the Horn of Africa. In: Aquatic Conservation and Management in Africa. University Press of Florida, Gainesville, pp.104-123.

\section{How to cite this article:}

Lemma, A., 2020. Fish production enhancement through modern fishery technology around Adami Tullu Jiddo Kombolcha District of Lake Ziway. Int. J. Curr. Res. Biosci. Plant Biol. 7(12), 7-15.

doi: https://doi.org/10.20546/ijcrbp.2020.712.002 